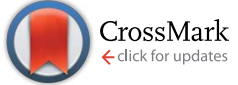

Cite this: RSC Adv., 2017, 7, 6193

Received 12th December 2016 Accepted 6th January 2017

DOI: 10.1039/c6ra28061g

www.rsc.org/advances

\section{C-7 modified flavonoids as novel tyrosyl-tRNA synthetase inhibitors $\uparrow$}

\author{
Zhu-Ping Xiao, ${ }^{\text {a }}$ Wei Wei, ${ }^{a}$ Qi Liu, ${ }^{a}$ Peng-Fei Wang, ${ }^{\text {b }}$ Xing Luo, ${ }^{a}$ Fang-Yuan Chen, ${ }^{a}$ \\ Yang Cao, ${ }^{a}$ Hong-Xia Huang, ${ }^{a}$ Mi-Mi Liu ${ }^{a}$ and Hai-Liang Zhu*ab
}

Twenty C-7 modified flavonoids were designed and synthesized. Biological evaluation in vitro indicated that compounds generated by SYBYL-X with high scores also showed good inhibitory activities against TyrRS. Compounds containing the nargenin core exhibit better enzyme inhibitory activities than other flavonoid cores, with (S)-5-hydroxy-4'-hydroxy-7-(2-morpholino-2-oxoethoxy)-2,3-dihydroflavone (b1) being the most active $\left(\mathrm{IC}_{50}=0.10 \pm 0.01 \mu \mathrm{M}\right)$ in all assayed compounds. All compounds were also assayed for antimicrobial activities against Staphylococcus aureus, Escherichia coli and Pseudomonas aeruginosa, and b1 also displayed excellent activity, showing 6-fold more potent than the marketed antibiotic ciprofloxacin. In comparison with Gram-positive organism, all these derivatives exhibited better activity against Gram-negative organism, and did not displayed significant differences between the two assayed Gram-negative strains (E. coli ATCC 8739 and P. aeruginosa ATCC 9027).

\section{Introduction}

Since the first therapeutic use of penicillin in 1941, each newly marketed antibiotic has invariably resulted in the emergence of drug-resistant pathogens, ${ }^{1-3}$ which has rendered marketed antibiotics less effective. ${ }^{4-6}$ One particularly troubling event is the widespread emergence of MRSA (methicillin resistant Staphylococcus aureus) strains, which are resistant to many major classes of drugs. ${ }^{7,8}$ Therefore, new classes of antibacterial agents are urgently needed to combat drug-resistant bacteria.

Flavonoids, natural products of the benzopyran class heterocycles, ubiquitously present in fruits and vegetables. ${ }^{9}$ In the past decades, a wide range of important biological activities have also been described, such as antioxidant, antibacterial, selective anticancer, anti-inflammatory and antiallergic properties. $^{10-16}$ However, most flavonoids were not developed as clinical drugs because of poor bioavailability (less than 5\%) and induction or inhibition of some metabolic enzymes. ${ }^{17}$ Therefore, great interest has been attracted in the field of structural modifications of the flavonoid skeleton for improving bioavailability and toxicity profiles. ${ }^{18}$

AaRSs (aminoacyl tRNA synthetases) play a crucial role in the process of protein synthesis, and are believed to be novel targets of antibacterial, antifungal and antiparasitic drugs. ${ }^{19-21}$ Recently,

${ }^{a}$ College of Chemistry and Chemical Engineering, Hunan Engineering Laboratory for Analyse and Drugs Development of Ethnomedicine in Wuling Mountains, Jishou University, Jishou 416000, P. R. China.E-mail: xiaozhuping2005@163.com

${ }^{b}$ State Key Laboratory of Pharmaceutical Biotechnology, Nanjing University, Nanjing 210093, P. R. China.E-mail: zhuhl@nju.edu.cn

$\dagger$ Electronic supplementary information (ESI) available. See DOI: 10.1039/c6ra28061g our efforts have focused on the development of novel TyrRS inhibitors based on modifications of 3-arylfuran-2 $(5 H)$-one core. $^{20,22,23} 4$-Hydroxyphenyl, a moiety of the substance of TyrRS, binds at the bottom of the active pocket, ${ }^{24}$ which is often observed in flavonoid molecules, such as naringenin from pomelo, apigenin from celery and daidzein from soybean (Fig. 1). Based on this consideration, modifications of flavonoid skeleton were here performed to mimic the substance of TyrRS (Tyrosyl-tRNA Synthetase), tyrosyl adenylate, as possible TyrRS inhibitors. Therefore, a series of novel flavonoid derivatives were designed and synthesized, and were subsequently evaluated for biological activities against a representative Gram-positive<smiles>O=C1C[C@H](c2ccc(O)cc2)Oc2cc(O)cc(O)c21</smiles><smiles>O=c1cc(-c2ccc(O)cc2)oc2cc(O)cc(O)c12</smiles><smiles>O=c1c(-c2ccc(O)cc2)coc2cc(O)ccc12</smiles><smiles>O=c1c(-c2ccc(O)cc2)coc2cc(O)cc(O)c12</smiles><smiles>O=c1cc(-c2ccccc2)oc2cc(O)cc(O)c12</smiles>

Fig. 1 Structures of representative flavonoids. 
organism (Staphylococcus aureus ATCC 6538) and two Gramnegative organisms (Escherichia coli ATCC 8739; Pseudomonas aeruginosa ATCC 9027). The results indicated that some of the synthesized compounds show very good antibacterial activities.

\section{Results and discussion}

\subsection{Design and virtual screen}

Based on scaffold hopping drug design, our laboratory recently developed several novel TyrRS inhibitors. ${ }^{25,26}$ As a continuation of this drug discovery program, scaffold hopping of tyrosyl adenylate was performed by Surflex Sim suite of SYBYL-X 2.1.1 (ref. 27) according to the hypothesis mentioned above. In details, tyrosyl adenylate were selected as the template for superposing with a series of typical $O$-graft flavonoids based on shape matching method (Fig. 2). Results revealed that 7-O-graft flavonoid was able to be the scaffold hopping structure of tyrosyl adenylate. To further determine the possibility of developing TyrRS inhibitors from this scaffold, compound library with C-7 side chain modifications were generated using the Library Design software module within the SYBYL-X environment. Subsequently, virtual screening was performed using docking mode of Surflex-Dock software module, where 20 possible conformations (poses) for each docked ligand were produced. The docked conformations of ligands were evaluated and ranked using Total_Score and Cscore (Concensus score)

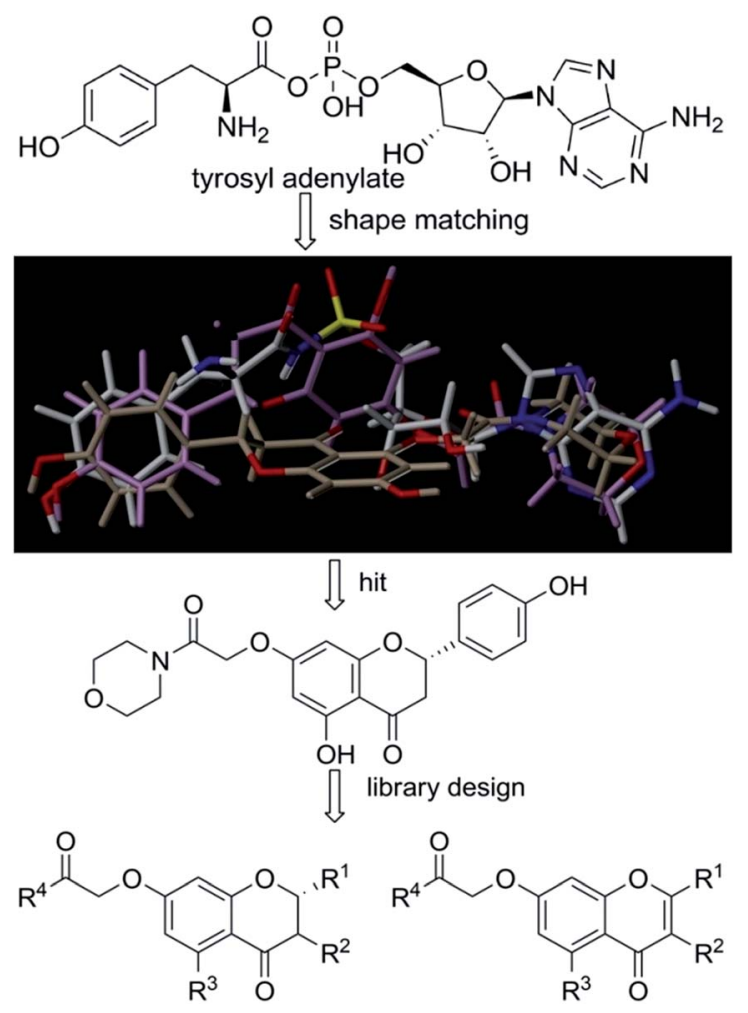

Fig. 2 Scaffold hopping and library design. Superpositions of tyrosyl adenylate (white) with a 7-O-graft flavonoid derivative (light purple) and 5 -O-graft flavonoid derivative (light brown) generated by Surflex Sim suite of SYBYL-X 2.1.1. modules. Compounds were selected according to synthesis possibility and values of Total_Score and Cscore, and the obtained top 20 compounds (b1-b20) were listed in Table 1.

\subsection{Synthesis and characterization}

The synthetic route illustrated in Schemes 1 and 2 was developed according to the reported methods with some modification, ${ }^{28-31}$ and the prepared compounds are depicted in Table 1. In general, deprotonation and alkylation of the 5-hydroxyl group is hardly since the hydrogen atom of the 5-hydroxyl group is attracted to the oxygen atom of the 4-carbonyl group forming intramolecular hydrogen bond. ${ }^{32}$ Chrysin therefore shows excellent $\mathrm{O}$-alkylation selectivity at $7-\mathrm{OH}$ in an alkaline environment, which followed by the production of compounds b16b20. This was supported the signal at about $\delta 12.8$ in ${ }^{1} \mathrm{H}$ NMRs of b16-b20, which was assigned to the hydrogen atom of 5-OH. Similarly, 5-OH in b1-b6 leaves intact in alkylation of their precursors naringenin and genistein. In comparison with $4^{\prime}$ $\mathrm{OH}, 7-\mathrm{OH}$ shows 2 orders of magnitude decrease in $\mathrm{p} K_{\mathrm{a}}$ values of naringenin and genistein, ${ }^{32-34}$ and alkylation of the hydroxyl groups occurs following a specific sequential position order: $7>$ $4^{\prime} \cdot{ }^{35,36}$ The signals at about $\delta 12.8$ and 9.6 in b1-b6 were assigned to $5-\mathrm{OH}$ and $4^{\prime}-\mathrm{OH}$, respectively. ${ }^{37-39}$ These facts suggested the selective $O$-alkylation of 7-OH.

\subsection{Inhibitory activities of flavonoid derivatives against TyrRS}

Compounds b1-b20 were synthesized (Schemes 1 and 2) to test for inhibitory activity against TyrRS from $E$. coli, and $\mathrm{IC}_{50} \mathrm{~S}$ of these compounds are presented in Table 1 . The main flavonoids involving in modifications are naringenin, genistein, $4^{\prime}$-O-methyldaidzein and chrysin. In these four series, derivatives from naringenin were determined to be the most potent, and compound b1 with a morpholine ring in the 7-side chain displayed $\mathrm{IC}_{50}$ of $0.10 \pm 0.01 \mu \mathrm{M}$ against TyrRS, being the most active. Substitution of the genistein core (b3) for naringenin core (b1) led to a slight decrease in potency. It was changed into daidzein or chrysin core, however, resulting in a significant decrease of potency with $\mathrm{IC}_{50}$ values of 6- to 70-fold increase (b1 vs. b12 or b19, b2 vs. b9 or b18). It can be seen that $\mathrm{R}^{4}$ at the C-7 side chain is also a major influence of molecule potency, and variation of the group at this position may result in large changes of $\mathrm{IC}_{50}$ values. N-Containing heterocyclic compounds were more active than alkyl or aromatic amino containing analogues, with evidences of anilino and benzylamino containing compounds (b7 and b8) being completely loss of activity against this enzyme. Replacement of morpholino with piperidino or $\mathrm{N}$-methylpiperazino caused 2 to 5 -fold decreases in potency, while a dramatic decrease was observed when it was changed into pyrrolidino group (b1 vs. b2, b12 vs. b9 and b19 vs. b18).

\subsection{Antibacterial activity}

All compounds were tested against representative Grampositive organism ( $S$. aureus ATCC 6538) and two Gramnegative organisms (E. coli ATCC 8739 and P. aeruginosa ATCC 9027), which are presented in Table 2 . The results revealed that 
Table 1 Scores of the obtained top 20 compounds from virtual screen and their inhibitory activities against TyrRS

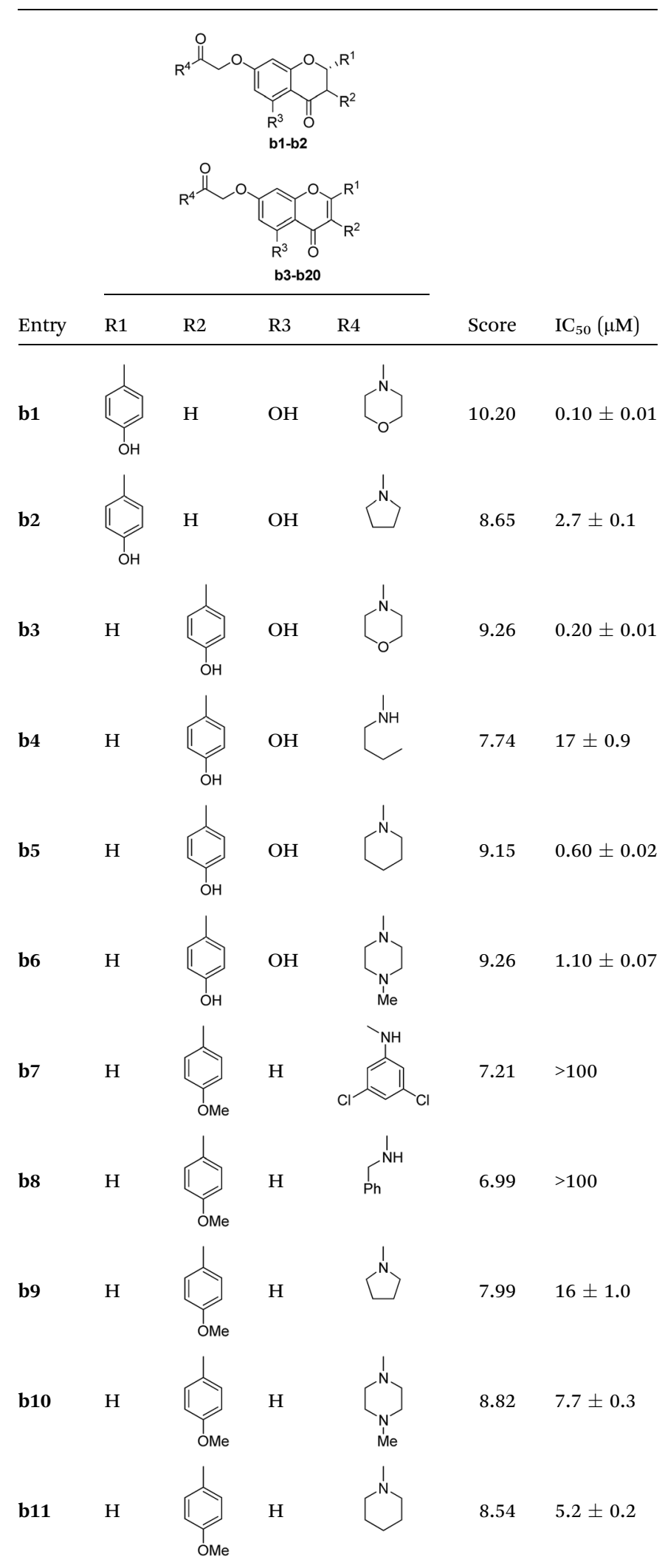

Table 1 (Contd.)

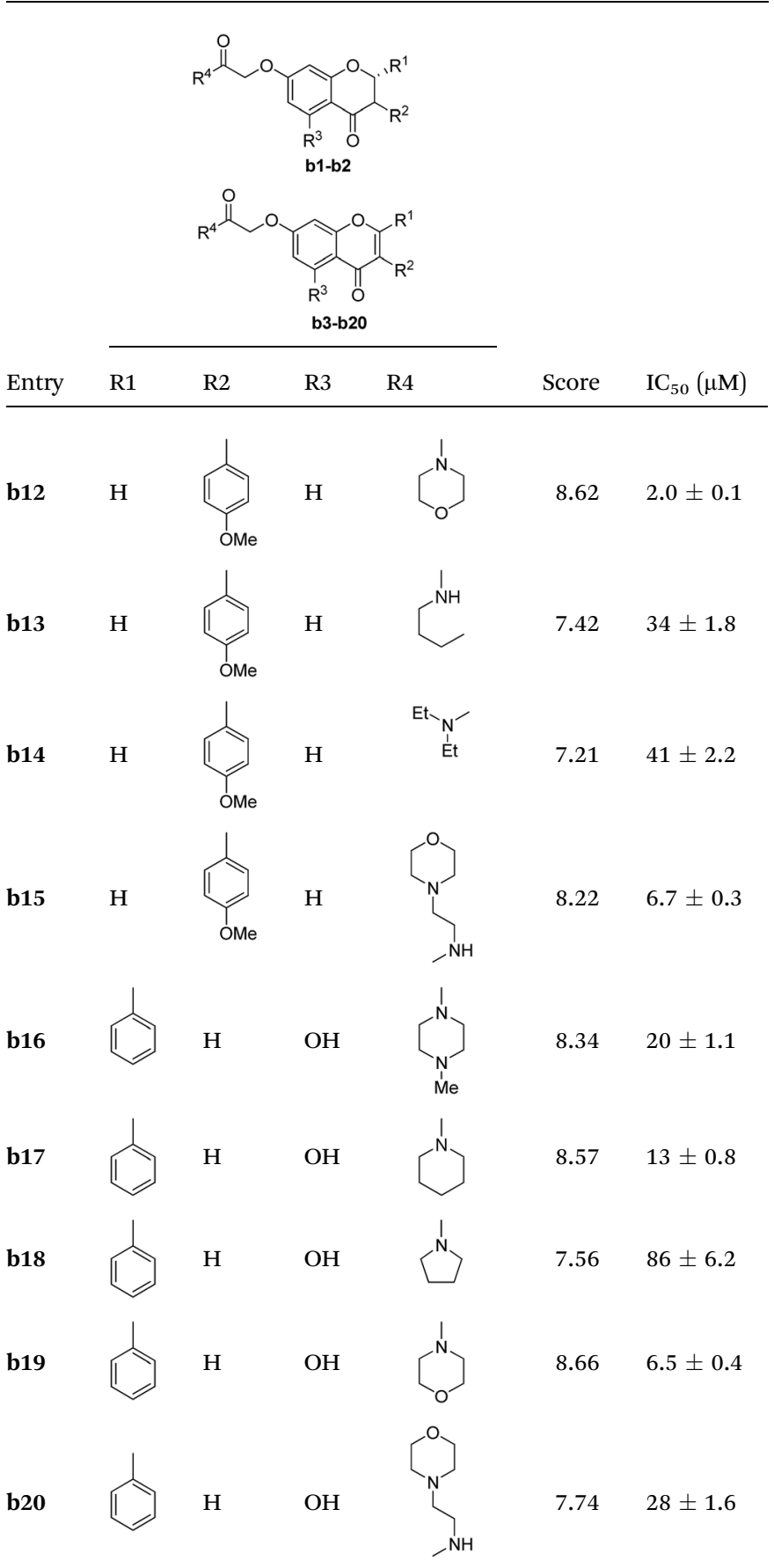




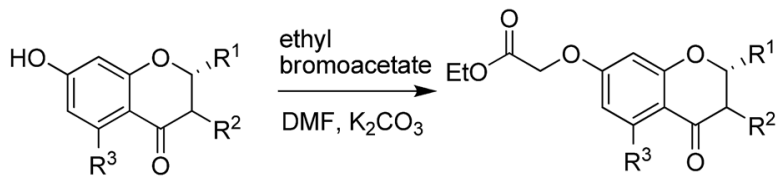<smiles>[R]c1cc(OCC(=O)OCC(C)C)cc2c1C(=O)C([R])C([R])O2</smiles>
a1: $\mathrm{R}^{1}=4$-hydroxyphenyl, $\mathrm{R}^{2}=\mathrm{H}, \mathrm{R}^{3}=\mathrm{OH}$;<smiles>[R]C(=O)COc1cc([R])c2c(c1)OC([R])C([R])C2=O</smiles>

b1-b2: see details in Table 1

Scheme 1 Synthetic route of compounds b1-b2<smiles>[R]c1oc2cc(OCC(=O)OCC)cc([R])c2c(=O)c1[R]</smiles><smiles>[R]c1oc2cc(OCC(=O)OCC)cc([R])c2c(=O)c1[R2]</smiles>
a2: $\mathrm{R}^{1}=4$-hydroxyphenyl, $\mathrm{R}^{2}=\mathrm{H}, \mathrm{R}^{3}=\mathrm{OH}$; a3: $\mathrm{R}^{1}=\mathrm{H}, \mathrm{R}^{2}=4$-hydroxyphenyl, $\mathrm{R}^{3}=\mathrm{OH}$; a4: $R^{1}=H, R^{2}=4-$ methoxyphenyl, $R^{3}=H$; a5: $\mathrm{R}^{1}=$ phenyl, $\mathrm{R}^{2}=\mathrm{H}, \mathrm{R}^{3}=\mathrm{OH}$.<smiles>[R]C(=O)COc1cc([R])c2c(=O)c([R])c([R])oc2c1</smiles>

b3-b20: see details in Table 1

Scheme 2 Synthetic route of compounds b3-b20.

compounds, b1, b3 and b5, showed better activities than marketed antibiotic ciprofloxacin against Gram-negative organisms, together with two compounds (b6 and b10) being compared to ciprofloxacin. Out of these compounds, b1 was the most active with $\mathrm{MIC}_{50}$ of $0.11 \mu \mathrm{g} \mathrm{mL} \mathrm{m}^{-1}$, showing 6-fold more potent than ciprofloxacin.

\subsection{In vitro toxicity}

As these derivatives were inhibitors against TyrRS, we studied the toxicity of active compounds measuring cytotoxicity $\left(\mathrm{EC}_{50}\right)$ against mammalian cells (HeLa). None of the derivatives showed significant toxicity up to $100 \mu \mathrm{M}$ concentration (Table 3 ), which indicates assayed compounds showed selectivity $>100$.

\subsection{Docking studies}

Molecular dockings of the most active compound b1 were performed to illustrate the binding mode and to provide an
Table 2 Inhibitory activity $\left(\mathrm{MIC}_{50}\right)$ of the synthesized compounds against pathogens ${ }^{a}$

\begin{tabular}{llll}
\hline & \multicolumn{2}{l}{$\mathrm{MIC}_{50}\left(\mu \mathrm{g} \mathrm{mL}^{-1}\right)$} & \\
\cline { 2 - 4 } Entry & $\mathrm{A}$ & $\mathrm{B}$ & $\mathrm{C}$ \\
\hline b1 & 0.11 & 0.29 & 0.59 \\
b2 & 1.8 & 2.7 & 14.8 \\
b3 & 0.37 & 0.55 & 1.6 \\
b4 & 44.3 & 56.1 & 47.8 \\
b5 & 0.55 & 0.71 & 9.3 \\
b6 & 0.67 & 1.2 & 10.9 \\
b7 & $>100$ & $>100$ & $>100$ \\
b8 & $>100$ & $>100$ & $>100$ \\
b9 & 30.2 & 42.4 & 35.5 \\
b10 & 1.0 & 2.2 & 12.9 \\
b11 & 2.7 & 3.0 & 6.8 \\
b12 & 15.3 & 18.7 & 29.4 \\
b13 & $>100$ & $>100$ & $>100$ \\
b14 & $>100$ & $>100$ & $>100$ \\
b15 & 10.2 & 14.2 & 25.6 \\
b16 & 70.4 & 94.9 & 82.7 \\
b17 & 18.5 & 22.7 & 31.3 \\
b18 & $>100$ & $>100$ & $>100$ \\
b19 & 6.7 & 8.5 & 17.8 \\
b20 & $>100$ & $>100$ & 98 \\
Ciprofloxacin & 0.67 & 0.81 & - \\
Penicillin G & - & - & 0.54
\end{tabular}

${ }^{a}$ (A) E. coli ATCC 8739; (B) P. aeruginosa ATCC 9027; (C) S. aureus ATCC 6538 .

Table 3 Cytotoxicity data of selected compounds

\begin{tabular}{ll}
\hline Entry & $\mathrm{EC}_{50}(\mu \mathrm{M})$ \\
\hline b1 & $>100$ \\
b3 & $>100$ \\
b5 & $>100$ \\
b6 & $>100$ \\
b10 & $>100$ \\
\hline
\end{tabular}

evidence for the potency of inhibition. Initially sketched b1 was subjected to energy minimization (10 000 iterations) by the Powell minimization standard method. The final b1 conformational coordinates were stored as a mol2 file. Accuracy docking was performed using the Surflex-Dock GeomX software module within the SYBYL-X 2.1.1 environment. Molecular docking results revealed that b1 docks favorably into the active site of TyrRS, and adopts a binding pose as that of cocrystallized ligand Tyr-AMS (5-O-[ $\mathrm{N}$-(L-tyrosyl)sulfamoyl]adenosine) (Fig. 3). Along the active site, the morpholino moiety packs in the upper cleft of the binding pocket, and forms hydrophobic interactions with Val 53, Leu 227 and Ile 228. Oxygen atom at C7 as a hydrogen bond acceptor receives two strong hydrogen bond interactions from Gly 197 and Asp 200 with $\mathrm{H} \cdots \mathrm{O}$ distances of 2.185 and $2.868 \AA$, while Asp 200 in turn as a acceptor builds another $\mathrm{O}-\mathrm{H} \cdots \mathrm{O}$ hydrogen bond with $5-\mathrm{OH}$. On the contrary, the B-ring of the naringenin core drops 


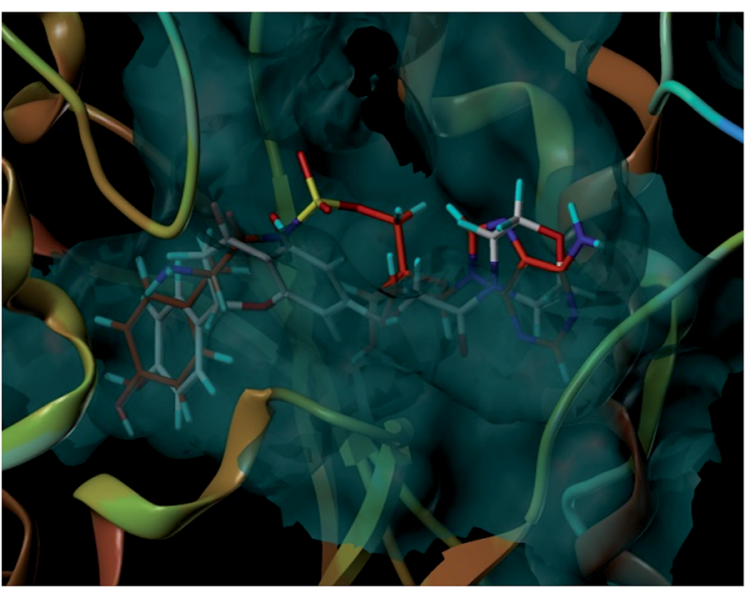

Fig. 3 Binding pose of compound b1 with TyrRS (shown as gray) and the original binding pose of co-crystal ligand Tyr-AMS (shown as red).

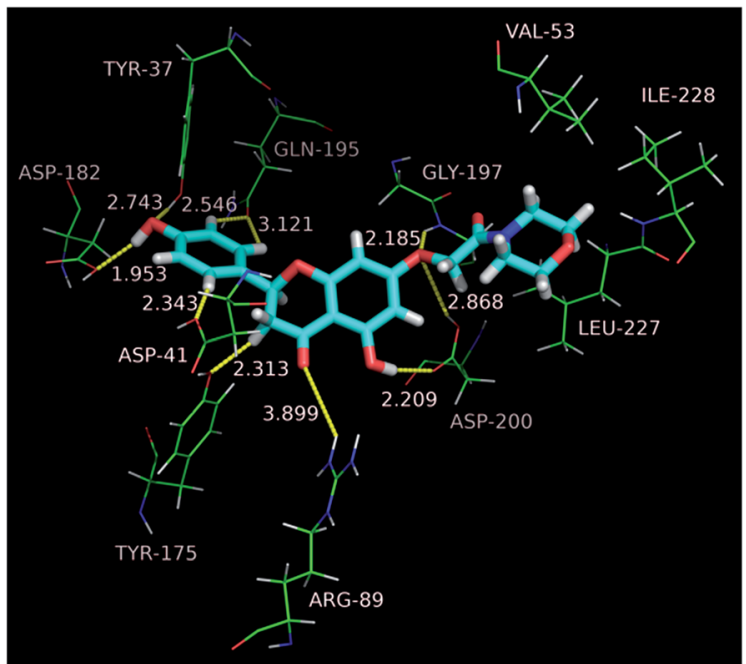

Fig. 4 Binding mode of compound b1 with TyrRS.

completely into the bottom of the binding pocket, with $\mathrm{OH}$ as the hydrogen bond acceptor as well as donor forming two hydrogen bonds $(\mathrm{O}-\mathrm{H} \cdots \mathrm{O})$ with Tyr 37 and Asp 182, respectively. In addition, three non-classical hydrogen bonds $(\mathrm{C}-\mathrm{H} \cdots$ O) were observed between B-ring and the enzyme backbone with $\mathrm{H} \cdots \mathrm{O}$ distances in the range of 2.3 to $3.2 \AA$. Hydrogen bonds built between $4-\mathrm{C}=\mathrm{O}$ and $\mathrm{Arg} 89,3-\mathrm{CH}_{2}$ and Tyr 175 also furnish important contributions to binding affinities (Fig. 4). The docking studies demonstrate that b1 strongly binds with TyrRS, powerfully supporting its excellent inhibitory potency in enzyme assays.

\section{Experimental}

\subsection{Chemistry}

All chemicals (reagent grade) used were purchased from Aldrich (U.S.A) and Sinopharm Chemical Reagent Co., Ltd (China). Separation of the compounds by column chromatography was carried out with silica gel 60 (200-300 mesh ASTM, E. Merck). The quantity of silica gel used was 30-70 times the weight charged on the column. Then, the eluates were monitored using TLC (thin-layer chromatography). Melting points (uncorrected) were determined on a XT4 MP apparatus (Taike Corp., Beijing, China). ESI mass spectra were obtained on a Mariner System 5304 mass spectrometer, and ${ }^{1} \mathrm{H}$ NMR and ${ }^{13} \mathrm{C}$ NMR spectra were recorded on Bruker AV-300 or 400 spectrometer at $25{ }^{\circ} \mathrm{C}$ with TMS and solvent signals allotted as internal standards. Chemical shifts were reported in ppm $(\delta)$. Elemental analyses were performed on a CHN-O-Rapid instrument and were within $\pm 0.4 \%$ of the theoretical values.

3.1.1 General procedure for preparation of compounds a1a4. ${ }^{40} \mathrm{~A}$ selected flavone (or isoflavone) $(10.0 \mathrm{mmol})$ and $\mathrm{K}_{2} \mathrm{CO}_{3}$ $(10.0 \mathrm{mmol})$ in DMF $(100 \mathrm{~mL})$ were stirred for $30 \mathrm{~min}$. After addition of ethyl bromoacetate $(15 \mathrm{mmol})$, the obtained mixture was stirred at $60-70{ }^{\circ} \mathrm{C}$ for $3-5 \mathrm{~h}$ (monitored by TLC), which were poured into $30 \mathrm{~mL}$ aqueous solution to dissolve $\mathrm{K}_{2} \mathrm{CO}_{3}$. Subsequently, $\mathrm{pH}$ value was adjusted to the range of 5.0-6.0 with $\mathrm{HCl}$, and the resulted mixture was extracted twice with 200 $\mathrm{mL}$ of EtOAc. The organic layer was dried over $\mathrm{MgSO}_{4}$ followed by removal of the solvent under reduced pressure. The residue was dissolved in acetone $(100 \mathrm{~mL})$, and the $\mathrm{pH}$ value was adjusted to the range of 9.0-10.0 with $0.1 \mathrm{M} \mathrm{NaOH}$. The mixture was stirred at $50-70{ }^{\circ} \mathrm{C}$ for $1-2 \mathrm{~h}$ (monitored by TLC). The $\mathrm{pH}$ value was adjusted to the range of 5.0-6.0 with $0.1 \mathrm{M} \mathrm{HCl}$. The precipitate was collected, which was purified by column chromatography on silica gel, eluting with $\mathrm{CHCl}_{3} / \mathrm{CH}_{3} \mathrm{OH}(\mathrm{v} / \mathrm{v}$, from $10 / 1$ to $50 / 1$, containing $0.3 \%$ of acetic acid) to give compound a1-a4 (Schemes 1 and 2) in yields of $75-90 \%$.

3.1.2 General procedure for preparation of compounds b1b21. ${ }^{41}$ Compound a $(3.0 \mathrm{mmol})$ was dissolved in $60 \mathrm{~mL}$ of dry $\mathrm{CH}_{2} \mathrm{Cl}_{2}$, followed by addition of 2-(1H-benzotriazole-1-yl)1,1,3,3-tetramethyluronium tetrafluoroborate (TBTU, 6.0 $\mathrm{mmol})$, an appropriate substituted amine $(4.5 \mathrm{mmol})$ and triethylamine $(9.0 \mathrm{mmol})$. The mixture was then stirred for $5-7 \mathrm{~h}$ at $60{ }^{\circ} \mathrm{C}$ (monitored by TLC). After the solvent was removed, the residue was partitioned between EtOAc and water. The organic layer was then dried over $\mathrm{MgSO}_{4}$ and concentrated under reduced pressure. Flash chromatography (EtOAc/petroleum ether, from $5 / 2$ to $2 / 3$ ) furnished compound b1-b20 (Schemes 1 and 2) in good yields.

3.1.2.1 (S)-5-Hydroxy-4'-hydroxy-7-(2-morpholino-2-oxoethoxy)2,3-dihydroflavone (b1). Light yellow powder, $57.4 \%$, mp 161$162{ }^{\circ} \mathrm{C} ;{ }^{1} \mathrm{H}$ NMR (DMSO): $2.60(\mathrm{dd}, J=17.2 \mathrm{~Hz}, J=3.0 \mathrm{~Hz}, 1 \mathrm{H}$ ); $3.29-3.32(\mathrm{~m}, 1 \mathrm{H}) ; 3.42(\mathrm{t}, J=6.8 \mathrm{~Hz}, 4 \mathrm{H}) ; 4.33(\mathrm{t}, J=7.2 \mathrm{~Hz}, 2 \mathrm{H})$; $4.82(\mathrm{~s}, 2 \mathrm{H}) ; 5.49(\mathrm{dd}, J=13.4 \mathrm{~Hz}, J=2.9 \mathrm{~Hz}, 1 \mathrm{H}) ; 6.07(\mathrm{dd}, J=$ $7.8 \mathrm{~Hz}, J=2.3 \mathrm{~Hz}, 2 \mathrm{H}) ; 6.79(\mathrm{~s}, 1 \mathrm{H}) ; 6.80(\mathrm{~s}, 1 \mathrm{H}) ; 7.33(\mathrm{~d}, J=$ $8.5 \mathrm{~Hz}, 2 \mathrm{H}) ; 9.62$ (s, 1H); 12.07 (s, 1H); EIMS m/z $399\left(\mathrm{M}^{+}\right)$. Anal. calcd for $\mathrm{C}_{21} \mathrm{H}_{21} \mathrm{NO}_{7}$ : $\mathrm{C}, 63.15 ; \mathrm{H}, 5.30 ; \mathrm{N}, 3.51$; found: $\mathrm{C}, 63.09 ; \mathrm{H}$, $5.31 ; \mathrm{N}, 3.51$.

3.1.2.2 (S)-5-Hydroxy-4'-hydroxy-7-(2-(pyrrolidin-1-yl)-2-oxoethoxy)-2,3-dihydrofla-vone (b2). Light yellow powder, 53.9\%, mp 260-262 ${ }^{\circ} \mathrm{C} ;{ }^{1} \mathrm{H}$ NMR (DMSO): $1.72-1.79$ (m, 2H); 1.84-1.91 (m, $2 \mathrm{H}) ; 2.71(\mathrm{dd}, J=17.1 \mathrm{~Hz}, J=3.0 \mathrm{~Hz}, 1 \mathrm{H}) ; 3.33-3.43(\mathrm{~m}, 5 \mathrm{H})$; $4.81(\mathrm{~s}, 2 \mathrm{H}) ; 5.48(\mathrm{dd}, J=11.1 \mathrm{~Hz}, J=2.9 \mathrm{~Hz}, 1 \mathrm{H}) ; 6.07(\mathrm{dd}, J=$ $7.8 \mathrm{~Hz}, J=2.3 \mathrm{~Hz}, 2 \mathrm{H}) ; 6.79(\mathrm{~s}, 1 \mathrm{H}) ; 6.81(\mathrm{~s}, 1 \mathrm{H}) ; 7.33$ (d, $J=$ 
$8.5 \mathrm{~Hz}, 2 \mathrm{H})$; 9.61 (s, 1H); 12.08 (s, 1H); EIMS m/z $383\left(\mathrm{M}^{+}\right)$. Anal. calcd for $\mathrm{C}_{21} \mathrm{H}_{21} \mathrm{NO}_{6}$ : C, 65.79; $\mathrm{H}, 5.52 ; \mathrm{N}, 3.65$; found: C, 65.83; $\mathrm{H}, 5.51 ; \mathrm{N}, 3.65$.

3.1.2.3 5-Hydroxy-4'-hydroxy-7-(2-morpholino-2-oxoethoxy) isoflavone (b3). White powder, $82.5 \%, \mathrm{mp} 235-237{ }^{\circ} \mathrm{C} ;{ }^{1} \mathrm{H}$ NMR (DMSO): 3.46 (t, $J=4.7 \mathrm{~Hz}, 4 \mathrm{H}) ; 3.59(\mathrm{t}, J=4.8 \mathrm{~Hz}, 2 \mathrm{H}) ; 3.64(\mathrm{t}, J$ $=4.8 \mathrm{~Hz}, 2 \mathrm{H}) ; 5.03(\mathrm{~s}, 2 \mathrm{H}) ; 6.44(\mathrm{~d}, J=2.5 \mathrm{~Hz}, 1 \mathrm{H}) ; 6.67(\mathrm{~d}, J=$ $2.3 \mathrm{~Hz}, 1 \mathrm{H}) ; 6.84(\mathrm{~d}, J=8.4 \mathrm{~Hz}, 2 \mathrm{H}) ; 7.40(\mathrm{~d}, J=8.3 \mathrm{~Hz}, 2 \mathrm{H}) ; 8.42$ (s, 1H); $9.63(\mathrm{~s}, 1 \mathrm{H}) ; 12.96(\mathrm{~s}, 1 \mathrm{H})$; EIMS $m / z 397\left(\mathrm{M}^{+}\right)$. Anal. calcd for $\mathrm{C}_{21} \mathrm{H}_{19} \mathrm{NO}_{7}$ : C, 63.47; $\mathrm{H}, 4.82 ; \mathrm{N}, 3.52$; found: C, 63.50; $\mathrm{H}$, $4.81 ; \mathrm{N}, 3.52$.

3.1.2.4 5-Hydroxy-4'-hydroxy-7-(2-butylamino-2-oxoethoxy) isoflavone (b4). White powder, 64.8\%, mp 203-205 ${ }^{\circ} \mathrm{C} ;{ }^{1} \mathrm{H}$ NMR (DMSO): 0.85-0.897 (t, $J=7.3 \mathrm{~Hz}, 3 \mathrm{H}) ; 1.23-1.32(\mathrm{~m}, 2 \mathrm{H})$; $1.34-$ $1.55(\mathrm{~m}, 2 \mathrm{H}) ; 3.14(\mathrm{q}, J=6.7 \mathrm{~Hz}, 2 \mathrm{H}) ; 4.62(\mathrm{~s}, 2 \mathrm{H}) ; 6.46(\mathrm{~d}, J=$ $2.3 \mathrm{~Hz}, 1 \mathrm{H}) ; 6.66(\mathrm{~d}, J=2.3 \mathrm{~Hz}, 1 \mathrm{H}) ; 6.84(\mathrm{~d}, J=8.6 \mathrm{~Hz}, 2 \mathrm{H}) ; 7.40$ $(\mathrm{d}, J=8.6 \mathrm{~Hz}, 2 \mathrm{H}) ; 8.17(\mathrm{t}, J=5.8 \mathrm{~Hz}, 1 \mathrm{H}) ; 8.43(\mathrm{~s}, 1 \mathrm{H}) ; 9.63(\mathrm{~s}$, $1 \mathrm{H}) ; 12.96(\mathrm{~s}, 1 \mathrm{H})$; EIMS $\mathrm{m} / z 383\left(\mathrm{M}^{+}\right)$. Anal. calcd for $\mathrm{C}_{21} \mathrm{H}_{21} \mathrm{NO}_{6}$ : C, 65.79; H, 5.52; N, 3.65; found: C, 65.74; H, 5.53; $\mathrm{N}, 3.65$.

3.1.2.5 5-Hydroxy-4'-hydroxy-7-(2-piperidino-2-oxoethoxy) isoflavone (b5). White powder, $65.5 \%, \mathrm{mp} 235-237{ }^{\circ} \mathrm{C} ;{ }^{1} \mathrm{H}$ NMR (DMSO): $1.44-1.47$ (m, 2H); 1.52-1.77 (m, 4H); 3.38-3.45 (m, $4 \mathrm{H}) ; 4.99(\mathrm{~s}, 2 \mathrm{H}) ; 6.42(\mathrm{~d}, J=2.2 \mathrm{~Hz}, 1 \mathrm{H}) ; 6.65(\mathrm{~d}, J=2.2 \mathrm{~Hz}, 1 \mathrm{H})$; $6.83(\mathrm{~d}, J=8.6 \mathrm{~Hz}, 2 \mathrm{H}) ; 7.40(\mathrm{~d}, J=8.5 \mathrm{~Hz}, 2 \mathrm{H}) ; 8.42(\mathrm{~s}, 1 \mathrm{H}) ; 9.63$ $(\mathrm{s}, 1 \mathrm{H}) ; 12.96(\mathrm{~s}, 1 \mathrm{H})$; EIMS $\mathrm{m} / \mathrm{z} 395\left(\mathrm{M}^{+}\right)$. Anal. calcd for $\mathrm{C}_{22} \mathrm{H}_{21} \mathrm{NO}_{6}$ : C, 66.83; H, 5.35; N, 3.54; found: C, 66.87; H, 5.31; $\mathrm{N}, 3.54$.

3.1.2.6 5-Hydroxy-4'-hydroxy-7-(2-(4-methylpiperazino)-2oxoethoxy)isoflavone (b6). White powder, $63.2 \%, \mathrm{mp} 193-195{ }^{\circ} \mathrm{C}$; ${ }^{1} \mathrm{H}$ NMR (DMSO): 3.51 (s, 3H); 3.85-3.94 (m, 4H); 4.08-4.23 (m, $4 \mathrm{H}) ; 4.62(\mathrm{~s}, 2 \mathrm{H}) ; 4.64(\mathrm{~d}, J=2.2 \mathrm{~Hz}, 1 \mathrm{H}) ; 6.66(\mathrm{~d}, J=2.3 \mathrm{~Hz}, 1 \mathrm{H})$; $6.84(\mathrm{~d}, J=8.6 \mathrm{~Hz}, 2 \mathrm{H}) ; 7.40(\mathrm{~d}, J=8.6 \mathrm{~Hz}, 2 \mathrm{H}) ; 8.44(\mathrm{~s}, 1 \mathrm{H}) ; 9.64$ $(\mathrm{s}, 1 \mathrm{H}) ; 12.96(\mathrm{~s}, 1 \mathrm{H})$; EIMS $\mathrm{m} / \mathrm{z} 410\left(\mathrm{M}^{+}\right)$. Anal. calcd for $\mathrm{C}_{22} \mathrm{H}_{22} \mathrm{~N}_{2} \mathrm{O}_{6}$ : C, 64.38; H, 5.40; N, 6.83; found: C, 64.34; H, 5.41; $\mathrm{N}, 6.84$.

3.1.2.7 4'-Methoxy-7-(2-(3,5-dichlorophenylamino)-2-oxoethoxy)isoflavone (b7). Light yellow powder, 82.4\%, mp $208-210{ }^{\circ} \mathrm{C} ;{ }^{1} \mathrm{H}$ NMR (DMSO): 3.79 (s, 3H); 4.95 (s, 2H); 7.00 (d, $J=8.8 \mathrm{~Hz}, 2 \mathrm{H})$; $7.14-7.30(\mathrm{~m}, 2 \mathrm{H}) ; 7.35(\mathrm{t}, J=1.9 \mathrm{~Hz}, 1 \mathrm{H}) ; 7.53(\mathrm{~d}, J=8.8 \mathrm{~Hz}, 2 \mathrm{H})$; 7.75 (d, $J=1.9 \mathrm{~Hz}, 2 \mathrm{H}) ; 8.09$ (d, $J=8.7 \mathrm{~Hz}, 1 \mathrm{H}) ; 8.45$ (s, 1H); 10.51 (s, 1H); EIMS $m / z 469\left(\mathrm{M}^{+}\right)$. Anal. calcd for $\mathrm{C}_{24} \mathrm{H}_{17} \mathrm{Cl}_{2} \mathrm{NO}_{5}$ : C, 61.29; $\mathrm{H}, 3.64 ; \mathrm{Cl}, 15.08 ; \mathrm{N}, 2.98$; found: C, 61.23; H, 3.64; Cl, 15.09; N, 2.98 .

3.1.2.8 4'-Methoxy-7-(2-benzylamino-2-oxoethoxy)isoflavone (b8). White powder, 57.8\%, mp $195-197{ }^{\circ} \mathrm{C} ;{ }^{1} \mathrm{H}$ NMR (DMSO): $3.79(\mathrm{~s}, 3 \mathrm{H}) ; 4.37(\mathrm{~d}, J=6.1 \mathrm{~Hz}, 2 \mathrm{H}) ; 4.76(\mathrm{~s}, 2 \mathrm{H}) ; 7.01(\mathrm{~d}, J=$ $8.8 \mathrm{~Hz}, 2 \mathrm{H}) ; 7.13-7.37$ (m, 7H); 7.54 (d, $J=8.7 \mathrm{~Hz}, 2 \mathrm{H}) ; 8.07$ (d, $J$ $=9.6 \mathrm{~Hz}, 1 \mathrm{H}) ; 8.44(\mathrm{~s}, 1 \mathrm{H}) ; 8.78(\mathrm{t}, J=6.1 \mathrm{~Hz}, 1 \mathrm{H}) ;$ EIMS $m / z 415$ $\left(\mathrm{M}^{+}\right)$. Anal. calcd for $\mathrm{C}_{25} \mathrm{H}_{21} \mathrm{NO}_{5}: \mathrm{C}, 72.28 ; \mathrm{H}, 5.10 ; \mathrm{N}, 3.37$; found: C, 72.23; H, 5.11; N, 3.37.

3.1.2.9 4'-Methoxy-7-(2-pyrrolidino-2-oxoethoxy)isoflavone (b9). Light yellow powder, 70.3\%, mp $139-140{ }^{\circ} \mathrm{C} ;{ }^{1} \mathrm{H}$ NMR (DMSO): 1.74-1.81 (m, 2H); 1.88-1.94 (m, 2H); 3.32 (t, $J=6.9 \mathrm{~Hz}, 2 \mathrm{H}) ; 3.45$ $(\mathrm{t}, J=6.8 \mathrm{~Hz}, 2 \mathrm{H}) ; 3.73(\mathrm{~s}, 3 \mathrm{H}) ; 4.85(\mathrm{~s}, 2 \mathrm{H}) ; 6.45(\mathrm{~d}, J=2.5 \mathrm{~Hz}, 1 \mathrm{H})$; $6.54(\mathrm{dd}, J=9.0 \mathrm{~Hz}, J=2.5 \mathrm{~Hz}, 1 \mathrm{H}) ; 6.89(\mathrm{~d}, J=8.6 \mathrm{~Hz}, 2 \mathrm{H}) ; 7.22$ $(\mathrm{d}, J=8.6 \mathrm{~Hz}, 2 \mathrm{H}) ; 8.01$ (d, $J=9.0 \mathrm{~Hz}, 1 \mathrm{H}) ; 8.45$ (s, 1H); EIMS $m / z$
$379\left(\mathrm{M}^{+}\right)$. Anal. calcd for $\mathrm{C}_{22} \mathrm{H}_{21} \mathrm{NO}_{5}$ : C, 69.64; H, 5.58; N, 3.69; found: C, 69.68; $\mathrm{H}, 5.57$; N, 3.69.

3.1.2.10 4'-Methoxy-7-(2-(4-methylpiperazino)-2-oxoethoxy) isoflavone (b10). White powder, 76.8\%, mp $178-180{ }^{\circ} \mathrm{C} ;{ }^{1} \mathrm{H} \mathrm{NMR}$ (DMSO): 2.23 (s, 3H); 2.27-2.34 (m, 2H); 2.37-2.43 (m, 2H); 3.45$3.52(\mathrm{~m}, 4 \mathrm{H}) ; 3.80(\mathrm{~s}, 3 \mathrm{H}) ; 5.05(\mathrm{~s}, 2 \mathrm{H}) ; 7.00(\mathrm{~d}, J=8.8 \mathrm{~Hz}, 2 \mathrm{H})$; $7.10(\mathrm{dd}, J=8.9 \mathrm{~Hz}, J=2.4 \mathrm{~Hz}, 1 \mathrm{H}) ; 7.15(\mathrm{~d}, J=2.4 \mathrm{~Hz}, 1 \mathrm{H}) ; 7.54$ $(\mathrm{d}, J=8.7 \mathrm{~Hz}, 2 \mathrm{H}) ; 8.04(\mathrm{~d}, J=8.9 \mathrm{~Hz}, 1 \mathrm{H}) ; 8.43(\mathrm{~s}, 1 \mathrm{H}) ;{ }^{13} \mathrm{C} \mathrm{NMR}$ (DMSO): 44.26, 46.01, 54.94, 55.60, 66.56, 102.02, 114.07, $115.49,118.23,123.79,124.51,127.30,130.53$; EIMS $m / z 408$ $\left(\mathrm{M}^{+}\right)$. Anal. calcd for $\mathrm{C}_{23} \mathrm{H}_{24} \mathrm{~N}_{2} \mathrm{O}_{5}$ : C, 67.63; H, 5.92; N, 6.86; found: $\mathrm{C}, 67.67 ; \mathrm{H}, 5.91 ; \mathrm{N}, 6.85$.

3.1.2.11 4'-Methoxy-7-(2-piperidino-2-oxoethoxy)isoflavone (b11). White powder, 59.8\%, mp 146-148 ${ }^{\circ} \mathrm{C} ;{ }^{1} \mathrm{H}$ NMR (DMSO): 1.41-1.47 (m, 2H); 1.51-1.65 (m, 4H); 3.38-3.46 (m, 4H); 3.80 (s, 3H); 5.04 (s, $2 \mathrm{H}) ; 7.01(\mathrm{~d}, J=8.7 \mathrm{~Hz}, 2 \mathrm{H}) ; 7.10(\mathrm{dd}, J=8.9 \mathrm{~Hz}, J=2.4 \mathrm{~Hz}, 1 \mathrm{H})$; $7.14(\mathrm{~d}, J=2.3 \mathrm{~Hz}, 1 \mathrm{H}) ; 7.54$ (d, $J=8.7 \mathrm{~Hz}, 2 \mathrm{H}) ; 8.04$ (d, $J=8.8 \mathrm{~Hz}$, $1 \mathrm{H}) ; 8.44(\mathrm{~s}, 1 \mathrm{H})$; EIMS $m / z 393\left(\mathrm{M}^{+}\right)$. Anal. calcd for $\mathrm{C}_{23} \mathrm{H}_{23} \mathrm{NO}_{5}$ : C, 70.21; H, 5.89; N, 3.56; found: C, 70.17; H, 5.90; N, 3.56.

3.1.2.12 4'-Methoxy-7-(2-morpholino-2-oxoethoxy)isoflavone (b12). White powder, 84.6\%, mp $186-188{ }^{\circ} \mathrm{C} ;{ }^{1} \mathrm{H}$ NMR (DMSO): 3.45-3.51 (m, 4H); 3.57-3.64 (m, 2H); 3.64-3.68 (m, 2H); 3.80 (s, $3 \mathrm{H}) ; 5.07(\mathrm{~s}, 2 \mathrm{H}) ; 7.01(\mathrm{~d}, J=8.7 \mathrm{~Hz}, 2 \mathrm{H}) ; 7.11(\mathrm{dd}, J=8.9 \mathrm{~Hz}, J=$ $2.4 \mathrm{~Hz}, 1 \mathrm{H}) ; 7.17$ (d, $J=2.4 \mathrm{~Hz}, 1 \mathrm{H}) ; 7.54$ (d, $J=8.7 \mathrm{~Hz}, 2 \mathrm{H}) ; 8.04$ $(\mathrm{d}, J=8.9 \mathrm{~Hz}, 1 \mathrm{H}) ; 8.43(\mathrm{~s}, 1 \mathrm{H})$; EIMS $m / z 395\left(\mathrm{M}^{+}\right)$. Anal. calcd for $\mathrm{C}_{22} \mathrm{H}_{21} \mathrm{NO}_{6}: \mathrm{C}, 66.83 ; \mathrm{H}, 5.35 ; \mathrm{N}, 3.54$; found: $\mathrm{C}, 66.88 ; \mathrm{H}$, $5.31 ; \mathrm{N}, 3.54$.

3.1.2.13 4'-Methoxy-7-(2-butylamino-2-oxoethoxy)isoflavone (b13). White crystal, 60.5\%, mp $148-152{ }^{\circ} \mathrm{C} ;{ }^{1} \mathrm{H}$ NMR (DMSO): 0.86 (t, $J=7.3 \mathrm{~Hz}, 3 \mathrm{H}) ; 1.28$ (p, $J=7.3 \mathrm{~Hz}, 2 \mathrm{H}) ; 1.42$ (p, $J=$ $7.1 \mathrm{~Hz}, 2 \mathrm{H}) ; 3.14$ (q, $J=6.7 \mathrm{~Hz}, 2 \mathrm{H}) ; 3.79(\mathrm{~s}, 3 \mathrm{H}) ; 4.66(\mathrm{~s}, 2 \mathrm{H})$; $7.00(\mathrm{~d}, J=8.7 \mathrm{~Hz}, 2 \mathrm{H}) ; 7.14(\mathrm{~d}, J=1.9 \mathrm{~Hz}, 1 \mathrm{H}) ; 7.14(\mathrm{dd}, J=$ $8.7 \mathrm{~Hz}, J=2.0 \mathrm{~Hz}, 1 \mathrm{H}) ; 7.53(\mathrm{~d}, J=8.7 \mathrm{~Hz}, 2 \mathrm{H}) ; 8.06$ (d, $J=$ $8.6 \mathrm{~Hz}, 1 \mathrm{H}) ; 8.21(\mathrm{t}, J=5.9 \mathrm{~Hz}, 1 \mathrm{H}) ; 8.44(\mathrm{~s}, 1 \mathrm{H})$; EIMS $\mathrm{m} / z 381$ $\left(\mathrm{M}^{+}\right)$. Anal. calcd for $\mathrm{C}_{22} \mathrm{H}_{23} \mathrm{NO}_{5}$ : C, 69.28; H, 6.08; N, 3.67; found: C, 69.23; H, 6.09; N, 3.67.

3.1.2.14 4'-Methoxy-7-(2-diethylamino-2-oxoethoxy)isoflavone (b14). Pink powder, 71.3\%, mp 124-126 ${ }^{\circ} \mathrm{C} ;{ }^{1} \mathrm{H}$ NMR (DMSO): $1.05(\mathrm{t}, J=7.1 \mathrm{~Hz}, 6 \mathrm{H}) ; 3.30(\mathrm{q}, J=6.9 \mathrm{~Hz}, 4 \mathrm{H}) ; 3.79(\mathrm{~s}, 3 \mathrm{H}) ; 5.01$ $(\mathrm{s}, 2 \mathrm{H}) ; 7.00(\mathrm{~d}, J=8.8 \mathrm{~Hz}, 2 \mathrm{H}) ; 7.09(\mathrm{dd}, J=8.4 \mathrm{~Hz}, J=2.4 \mathrm{~Hz}$, $1 \mathrm{H}) ; 7.10$ (d, $J=2.4 \mathrm{~Hz}, 1 \mathrm{H}) ; 7.53$ (d, $J=8.7 \mathrm{~Hz}, 2 \mathrm{H}) ; 8.04$ (d, $J=$ $9.1 \mathrm{~Hz}, 1 \mathrm{H}) ; 8.43(\mathrm{~s}, 1 \mathrm{H})$; EIMS $m / z 381\left(\mathrm{M}^{+}\right)$. Anal. calcd for $\mathrm{C}_{22} \mathrm{H}_{23} \mathrm{NO}_{5}$ : C, 69.28; H, 6.08; N, 3.67; found: C, 69.33; H, 6.07; $\mathrm{N}, 3.67$.

3.1.2.15 4'-Methoxy-7-(2-(2-morpholino)ethylamino-2-oxoethoxy) isoflavone (b15). White powder, 75.5\%, mp $178-180{ }^{\circ} \mathrm{C} ;{ }^{1} \mathrm{H} \mathrm{NMR}$ (DMSO): 2.30-2.44 (m, 6H); 3.28 (q, $J=6.5 \mathrm{~Hz}, 2 \mathrm{H}) ; 3.55(\mathrm{t}, J=$ $4.6 \mathrm{~Hz}, 4 \mathrm{H}) ; 3.80(\mathrm{~s}, 3 \mathrm{H}) ; 4.69(\mathrm{~s}, 2 \mathrm{H}) ; 7.01(\mathrm{~d}, J=8.7 \mathrm{~Hz}, 2 \mathrm{H})$; $7.15(\mathrm{~d}, J=2.3 \mathrm{~Hz}, 1 \mathrm{H}) ; 7.16(\mathrm{dd}, J=8.6 \mathrm{~Hz}, J=2.4 \mathrm{~Hz}, 1 \mathrm{H}) ; 7.54$ $(\mathrm{d}, J=8.8 \mathrm{~Hz}, 2 \mathrm{H}) ; 8.08(\mathrm{~d}, J=9.6 \mathrm{~Hz}, 1 \mathrm{H}) ; 8.12(\mathrm{t}, J=5.7 \mathrm{~Hz}$, $1 \mathrm{H}) ; 8.44(\mathrm{~s}, 1 \mathrm{H})$; EIMS $m / z 438\left(\mathrm{M}^{+}\right)$. Anal. calcd for $\mathrm{C}_{24} \mathrm{H}_{26} \mathrm{~N}_{2} \mathrm{O}_{6}$ : C, 65.74; H, 5.98; N, 6.39; found: C, 65.71; H, 5.99; N, 6.40.

3.1.2.16 5-Hydroxy-7-(2-(4-methyl)piperazino-2-oxoethoxy) flavone (b16). Light yellow powder, 77.8\%, mp $144-146{ }^{\circ} \mathrm{C} ;{ }^{1} \mathrm{H}$ NMR (DMSO): 2.85 (s, 3H); 2.95-3.20 (m, 4H); 3.35-3.60 (m, 4H); $5.09(\mathrm{~s}, 2 \mathrm{H}) ; 6.47(\mathrm{~d}, J=2.2 \mathrm{~Hz}, 1 \mathrm{H}) ; 6.85(\mathrm{~d}, J=2.2 \mathrm{~Hz}, 1 \mathrm{H}) ; 7.06$ (s, 1H); 7.58-7.67 (m, 3H); $8.10(\mathrm{~d}, J=8.2 \mathrm{~Hz}, 2 \mathrm{H}) ; 12.85(\mathrm{~s}, 1 \mathrm{H})$; 
EIMS $m / z 394\left(\mathrm{M}^{+}\right)$. Anal. calcd for $\mathrm{C}_{22} \mathrm{H}_{22} \mathrm{~N}_{2} \mathrm{O}_{5}$ : C, 66.99; $\mathrm{H}, 5.62$; N, 7.10; found: C, 66.94; H, 5.61; N, 7.11.

3.1.2.17 5-Hydroxy-7-(2-piperidino-2-oxoethoxy)flavone (b17). Yellow powder, $61.7 \%$, mp 181-183 ${ }^{\circ} \mathrm{C} ;{ }^{1} \mathrm{H}$ NMR (DMSO): $1.40-$ 1.47 (m, 2H); 1.57-1.62 (m, 4H); 3.39-3.46 (m, 4H); 5.00 (s, 2H); $6.42(\mathrm{~d}, J=2.2 \mathrm{~Hz}, 1 \mathrm{H}) ; 6.82(\mathrm{~d}, J=2.2 \mathrm{~Hz}, 1 \mathrm{H}) ; 7.06(\mathrm{~s}, 1 \mathrm{H})$; 7.57-7.66 (m, 3H); 8.11 (d, $J=6.6 \mathrm{~Hz}, 2 \mathrm{H}) ; 12.82(\mathrm{~s}, 1 \mathrm{H})$; EIMS $m /$ $z 379\left(\mathrm{M}^{+}\right)$. Anal. calcd for $\mathrm{C}_{22} \mathrm{H}_{21} \mathrm{NO}_{5}: \mathrm{C}, 69.64 ; \mathrm{H}, 5.58 ; \mathrm{N}, 3.69$; found: C, 69.59; H, 5.59; N, 3.69.

3.1.2.18 5-Hydroxy-7-(2-pyrrolidino-2-oxoethoxy)flavone (b18). Light yellow powder, 80.6\%, mp $159-161{ }^{\circ} \mathrm{C} ;{ }^{1} \mathrm{H}$ NMR (DMSO): $1.79(\mathrm{p}, J=6.8 \mathrm{~Hz}, 2 \mathrm{H}) ; 1.92(\mathrm{p}, J=6.8 \mathrm{~Hz}, 2 \mathrm{H}) ; 3.34(\mathrm{t}, J=6.8 \mathrm{~Hz}$, $2 \mathrm{H}$, overlapping with signals of water); $3.48(\mathrm{t}, J=6.8 \mathrm{~Hz}, 2 \mathrm{H})$; $4.92(\mathrm{~s}, 2 \mathrm{H}) ; 6.42(\mathrm{~d}, J=2.2 \mathrm{~Hz}, 1 \mathrm{H}) ; 6.82(\mathrm{~d}, J=2.2 \mathrm{~Hz}, 1 \mathrm{H}) ; 7.06$ (s, 1H); 7.57-7.66 (m, 3H); $8.11(\mathrm{~d}, J=6.6 \mathrm{~Hz}, 2 \mathrm{H}) ; 12.82(\mathrm{~s}, 1 \mathrm{H})$; EIMS $m / z 365\left(\mathrm{M}^{+}\right)$. Anal. calcd for $\mathrm{C}_{21} \mathrm{H}_{19} \mathrm{NO}_{5}$ : C, 69.03; H, 5.24; N, 3.83; found: C, 69.08; H, 5.23; N, 3.83.

3.1.2.19 5-Hydroxy-7-(2-morpholino-2-oxoethoxy)flavone (b19). Yellow powder, 58.7\%, mp 212-213 ${ }^{\circ} \mathrm{C} ;{ }^{1} \mathrm{H}$ NMR (DMSO): $3.42-$ 3.49 (m, 4H); 3.53-3.61 (m, 2H); 3.61-3.68 (m, 2H); 5.03 (s, 2H); $6.44(\mathrm{~d}, J=2.3 \mathrm{~Hz}, 1 \mathrm{H}) ; 6.82(\mathrm{~d}, J=2.3 \mathrm{~Hz}, 1 \mathrm{H}) ; 7.06(\mathrm{~s}, 1 \mathrm{H})$; 7.577.66 (m, 3H); 8.10 (d, $J=6.6 \mathrm{~Hz}, 2 \mathrm{H}) ; 12.82$ (s, 1H); EIMS m/z 381 $\left(\mathrm{M}^{+}\right)$. Anal. calcd for $\mathrm{C}_{21} \mathrm{H}_{19} \mathrm{NO}_{6}: \mathrm{C}, 66.13 ; \mathrm{H}, 5.02 ; \mathrm{N}, 3.67$; found: C, 66.09; H, 5.03; N, 3.67.

3.1.2.20 5-Hydroxy-7-(2-(2-morpholino)ethylamino-2-oxoethoxy) flavone (b20). ${ }^{42}$ Yellow powder, 63.4\%, mp 216-217 ${ }^{\circ} \mathrm{C} ;{ }^{1} \mathrm{H}$ NMR (DMSO): 2.30-2.42 (m, 4H); 3.20-3.33 (m, 4H); 3.45-3.60 (m, 4H); $4.67(\mathrm{~s}, 2 \mathrm{H}) ; 6.46(\mathrm{~d}, J=2.2 \mathrm{~Hz}, 1 \mathrm{H}) ; 6.85(\mathrm{~d}, J=2.3 \mathrm{~Hz}, 1 \mathrm{H}) ; 7.08$ (s, 1H); 7.58-7.67 (m, 3H); 8.11 (d, $J=6.6 \mathrm{~Hz}, 2 \mathrm{H}) ; 8.85$ (bs, 1H); 12.83 (s, 1H); EIMS $m / z 424\left(\mathrm{M}^{+}\right)$. Anal. calcd for $\mathrm{C}_{23} \mathrm{H}_{24} \mathrm{~N}_{2} \mathrm{O}_{6}: \mathrm{C}$, 65.08; H, 5.70; N, 6.60; found: C, 65.11; H, 5.69; N, 6.59.

\subsection{Extraction of the TyrRS and enzyme assay}

TyrRS was over-expressed in E. coli and purified to near homogeneity ( $\sim 98 \%$ as judged by SDS-PAGE (sodium dodecyl sulfate polyacrylamide gel electrophoresis)) using standard purification procedures. TyrRS activity was measured by aminoacylation using modifications to previously described methods. ${ }^{43}$ The assays were performed at $37{ }^{\circ} \mathrm{C}$ in a mixture containing (final concentrations) $100 \mathrm{mM}$ Tris/Cl pH 7.9, $50 \mathrm{mM} \mathrm{KCl}, 16 \mathrm{mM} \mathrm{MgCl}_{2}, 5 \mathrm{mM}$ ATP (adenosine triphosphate), $3 \mathrm{mM}$ DTT (DL-dithiothreitol), $4 \mathrm{mg} \mathrm{mL}^{-1}$ E. coli MRE600 tRNA (Roche) and $10 \mu \mathrm{M}$ L-tyrosine $\left(0.3 \mu \mathrm{M} \mathrm{L}_{\mathrm{L}}\left[\right.\right.$ ring-3,5- $\left.{ }^{3} \mathrm{H}\right]$ tyrosine (PerkinElmer, specific activity: $1.48-2.22 \mathrm{TBq} \mathrm{mmol}^{-1}$ ), $10 \mu \mathrm{M}$ carrier). TyrRS (0.2 nM) was preincubated with a range of inhibitor concentrations for $10 \mathrm{~min}$ at room temperature followed by the addition of pre-warmed mixture at $37{ }^{\circ} \mathrm{C}$. After specific intervals, the reaction was terminated by adding aliquots of the reaction mix into ice-cold $7 \%$ trichloroacetic acid and harvesting onto $0.45 \mathrm{~mm}$ hydrophilic Durapore filters (Millipore Multiscreen 96-well plates) and counted by liquid scintillation. The rate of reaction in the experiments was linear with respect to protein and time with less than 50\% total tRNA acylation. $\mathrm{IC}_{50} \mathrm{~s}$ correspond to the concentration at which half of the enzyme activity is inhibited by the compound. The results are presented in Table 1.

\subsection{Antimicrobial activity}

The antibacterial activities of the synthesized compounds were tested against Gram-positive bacterial strain (Staphylococcus aureus ATCC 6538, penicillin G sodium as positive control) and two Gram-negative bacterial strains (Escherichia coli ATCC 8739 and Pseudomonas aeruginosa ATCC 9027, ciprofloxacin as positive control). The MTT (methylthiazolyldiphenyl-tetrazolium bromide) proliferation assay was used to measure the $\mathrm{MIC}_{50} \mathrm{~S}$ of the test compounds by determining the absorbance of the cells in culture. ${ }^{44}$ A stock solution of the synthesized compound $\left(1000 \mu \mathrm{g} \mathrm{mL} \mathrm{m}^{-1}\right)$ in DMSO was prepared with different concentrations using sterilized liquid medium (50\% (v/v) of DMSO in PBS (phosphate-buffered saline)). A specified quantity of the medium containing the test compound was added into 96-well plates, which was replaced by the sterilized liquid medium as blank control. Suspension of the microorganism was prepared to contain approximate $10^{5} \mathrm{cfu} \mathrm{mL}^{-1}$ and applied to 96 -well plates with serially diluted compounds (or blank control) to be tested and incubated at $37{ }^{\circ} \mathrm{C}$. In the case of fungi, plates were incubated at $28{ }^{\circ} \mathrm{C}$. Fifty $\mu \mathrm{L}$ of PBS containing $3 \mathrm{mg}$ of MTT per $\mathrm{mL}$ was added to each well. Incubation was continued for $4-5 \mathrm{~h}$, then $100 \mu \mathrm{L}$ of $10 \%$ sodium dodecyl sulfate containing $5 \%$ isopropanol and $10 \mathrm{~mol} \mathrm{~mL}{ }^{-1} \mathrm{HCl}$ was added to extract the dye. After 8-10 h of incubation, the control OD (optical density) value (at $570 \mathrm{~nm}$ ) should be controlled under 1.0-2.0 to achieve reliable results. The observed $\mathrm{MIC}_{50}$ s were presented in Table 2 .

\subsection{Cytotoxicity assay ${ }^{45}$}

Cytotoxicity of selected compounds was assessed against an HeLa cell line. The cells were grown in a 96-well plate in DMEM media supplemented with $10 \%$ fetal bovine serum and 5\% penicillin-streptomycin until they reached $70-80 \%$ confluency. The cells were then treated with serially diluted compounds. Two controls were made, one containing no cells (blank control) and the other control containing cells with no compounds (control). Cells were incubated for $24 \mathrm{~h}$ at $37{ }^{\circ} \mathrm{C}$ under $5 \% \mathrm{CO}_{2}$ atmosphere. After $24 \mathrm{~h}$, the supernatant was carefully removed and $100 \mu \mathrm{L}$ of $5 \mathrm{mg} \mathrm{mL}{ }^{-1}$ concentration MTT solution was added to each well. The plate was incubated for $3 \mathrm{~h}$ at $37^{\circ} \mathrm{C}$ under $5 \% \mathrm{CO}_{2}$ atmosphere. The cells were then treated with 100 $\mu \mathrm{L}$ of DMSO to solubilize formazan crystals. The plate was then read at $570 \mathrm{~nm}$. The quantity of viable cells after treatment with each compound was expressed as a percentage of the control.

\subsection{Protocol of docking study}

The X-ray structure of TyrRS from Bacillus stearothermophilus was downloaded from the Protein Data Bank (PDB code: 3ts1) ${ }^{\mathbf{2 4}}$ and was modified by adding hydrogen atoms and removing water as well as cocrystallized substrate (tyrosinyl adenylate) using SYBYL-X version 2.1.1 software suite (Tripos, Inc., St. Louis, MO). ${ }^{27}$ The active site was defined as all the amino acid residues confined within a $5 \AA$ radius sphere centered about tyrosinyl adenylate, and the composite structure without original ligand was utilized as the in silico model for docking studies. Default parameters and values within the minimization 
dialogue were used except where otherwise mentioned. The docked conformations of ligands were evaluated and ranked using Surflex-Dock and four scoring functions implemented in the Cscore software module within the SYBYL-X environment. The Cscore module allowed consensus scoring that integrated multiple well-known scoring functions such as ChemScore, DScore, G-Score and PMF-Score to evaluate docked ligand conformations. ${ }^{46}$

\section{Conclusions}

A series of flavonoid derivatives was designed as TyrRS inhibitors based on scaffold hopping drug design. They were generated by Library Design software module within the SYBYL-X environment. Twenty compounds with top scores were obtained, and nineteen of them were reported for the first time. Enzyme assays identified three compounds showing excellent inhibitory activities against TyrRS with $\mathrm{IC}_{50}$ lower than $1 \mu \mathrm{M}$. In general, all the assayed compounds exhibited better activity against Gram-negative organism than Gram-positive organism. Furthermore, compounds with good inhibition against TyrRS also exhibit good antibacterial activities. Out of these compounds, b1 is the most active, which structurally containing a nargenin core with $\mathrm{MIC}_{50}$ of $0.11 \mu \mathrm{g} \mathrm{mL}^{-1}$ against $E$. coli ATCC 8739 shows 6-fold more potent than marketed antibiotic ciprofloxacin, and further investigations are being carried out in our laboratory. These findings together with molecular docking studies revealed that antibacterial activities of these flavonoid based amides may be caused by their inhibition of TyrRS, and compounds with a naringenin core are worth to be modified for discovery of novel antibacterial agents.

\section{Conflict of interest}

The authors declare no conflict of interest.

\section{Acknowledgements}

The work was financed by grants from National Natural Science Foundation of China (grant No. 21262013 and 81273382), by a Project supported by Hunan Provincial Natural Science Foundation of China (grant No. 2015JJ2116).

\section{Notes and references}

1 S. B. Levy and B. Marshall, Nat. Med., 2004, 10, S122-S129.

2 P. Fernandes, Nat. Biotechnol., 2006, 24(12), 1497-1503.

3 F. Fontaine, A. Hequet, A. S. Voisin-Chiret, B. Alexandre, L. Aurélien, C. Thierry, J. Claude and R. Sylvain, J. Med. Chem., 2014, 57(6), 2536-2548.

4 D. J. Payne, M. N. Gwynn, D. J. Holmes and D. L. Pompliano, Nat. Rev. Drug Discovery, 2007, 6(1), 29-40.

5 M. A. Fischbach and C. T. Walsh, Science, 2009, 325(5944), 1089-1093.

6 S. P. Kawatkar, T. A. Keating, N. B. Olivier, J. N. Breen, O. M. Green, S. Y. Guler, M. F. Hentemann, J. T. Loch,
A. R. McKenzie, J. V. Newman, L. J. Otterson and G. Martinez-Botella, J. Med. Chem., 2014, 57(11), 4584-4597. 7 E. Klein, D. L. Smith and R. Laxminarayan, Emerging Infect. Dis., 2007, 13(12), 1840-1846.

8 T. Lam, M. T. Hilgers, M. L. Cunningham, B. P. Kwan, K. J. Nelson, V. Brow-Driver, V. Ong, M. Trzoss, G. Hough, K. G. Shaw and J. Finn, J. Med. Chem., 2014, 57(3), 651-668.

9 A. K. Verma and R. Pratap, Tetrahedron, 2012, 68(41), 85238538.

10 R. Landolfi, R. L. Mower and M. Steiner, Biochem. Pharmacol., 1984, 33(9), 1525-1530.

11 P. A. Berg and P. T. Daniel, Prog. Clin. Biol. Res., 1988, 280, 157-171.

12 S. Gupta, F. Afaq and H. Mukhtar, Biochem. Biophys. Res. Commun., 2001, 287(4), 914-920.

13 L. C. Chiang, L. T. Ng, I. C. Lin, P. L. Kuo and C. C. Lin, Cancer Lett., 2006, 237(2), 207-214.

14 P. W. Snijman, E. Joubert, D. Ferreira, X. C. Li, Y. Q. Ding, I. R. Green and W. C. A. Gelderblom, J. Agric. Food Chem., 2009, 57(15), 6678-6684.

15 M. Dueñas, S. González-Manzano, A. González-Paramás and C. Santos-Buelga, J. Pharm. Biomed. Anal., 2010, 51(2), 443449.

16 H. Gao, H. Wang and J. Peng, Cell Biochem. Biophys., 2014, 69(1), 27-34.

17 L. Tang, Q. Feng, J. Zhao, L. N. Dong, W. Liu, C. H. Yang and Z. Q. Liu, Food Chem. Toxicol., 2012, 50(5), 1460-1467.

18 M. Singh, M. Kaur and O. Silakari, Eur. J. Med. Chem., 2014, 84, 206-239.

19 T. J. Bullwinkle and M. Ibba, Proc. Natl. Acad. Sci. U. S. A., 2016, 113(8), 2252-2257.

20 Z. P. Xiao, W. Wei, P. F Wang, W. K. Shi, N. Zhu, M. Q. Xie, Y. W. Sun, L. X. Li, Y. X. Xie, L. S. Zhu, N. Tang, H. OuYang, X. H. Li, G. C. Wang and H. L. Zhu, Eur. J. Med. Chem., 2015, 102, 631-638.

21 P. V. S. Mohana, R. Sankaranarayanan, M. Udayakumar and S. Thamotharan, Res. J. Pharm., Biol. Chem. Sci., 2015, 6(3), 1737-1743.

22 X. D. Wang, R. C. Deng, J. J. Dong, Z. Y. Peng, X. M. Gao, S. T. Li, W. Q. Lin, C. L. Lu, Z. P. Xiao and H. L. Zhu, Bioorg. Med. Chem., 2013, 21(17), 4914-4922.

23 X. D. Wang, W. Wei, P. F. Wang, Y. T. Tang, R. C. Deng, B. Li, S. S. Zhou, J. W. Zhang, L. Zhang, Z. P. Xiao, H. Ou-Yang and H. L. Zhu, Bioorg. Med. Chem., 2014, 22(14), 3620-3628.

24 P. Brick, T. N. Bhat and D. M. Blow, J. Mol. Biol., 1989, 208(1), 83-98.

25 Z. P. Xiao, X. B. He, Z. Y. Peng, T. J. Xiong, J. Peng, L. H. Chen and H. L. Zhu, Bioorg. Med. Chem., 2011, 19(5), 1571-1579.

26 W. Wei, W. K. Shi, P. F. Wang, X. T. Zeng, P. Li, J. R. Zhang, Q. Li, Z. P. Tang, J. Peng, L. Z. Wu, M. Q. Xie, C. Liu, X. H. Li, Y. C. Wang, Z. P. Xiao and H. L. Zhu, Bioorg. Med. Chem., 2015, 23(20), 6602-6611.

27 SYBYL Molecular Modeling Software, version SYBYL-X 2.1, Tripos Inc., St. Louis, MO, 2015.

28 E. R. Lee, Y. J. Kang, H. Y. Choi, G. H. Kang, J. H. Kim, B. W. Kim, Y. S. Han, S. Y. Nah and H. D. Paik, Biol. Pharm. Bull., 2007, 30, 2394-2398. 
29 M. Pal, R. Dakarapu, K. Parasuraman, V. Subramanian and K. R. Yeleswarapu, J. Org. Chem., 2005, 70, 7179-7187.

30 K. Dahlén, M. Grøtli and K. Luthman, Synlett, 2006, 897-900.

$31 \mathrm{M}$. Pal, V. Subramanian, K. Parasuraman and K. R. Yeleswarapu, Tetrahedron, 2003, 59, 9563-9570.

32 G. J. Nan, J. Shi, Y. R. Huang, J. Sun, J. H. Lv, G. D. Yang and Y. P. Li, J. Chem. Eng. Data, 2014, 59, 1304-1311.

33 I. Kron, Z. Pudychová-Chovanová, B. Veliká, J. Guzy and P. Perjési, Monatsh. Chem., 2012, 143, 13-17.

34 A. Dhainaut, G. Lewin, E. Canet, M. Lonchampt and Y. Rolland, US 5889003, 1999.

35 M. Bouktaib, S. Lebrun, A. Atmani and C. Rolando, Tetrahedron, 2002, 58, 10001-10009.

36 Q. G. Mei, C. Wang, W. C. Yuan and G. L. Zhang, Beilstein J. Org. Chem., 2015, 11, 288-293.

37 N. Ohta, G. Kuwata, H. Akahori and T. Watanabe, Agric. Biol. Chem., 1979, 43(7), 1415-1419.

38 J. M. Hastings, M. K. Hadden and B. S. J. Blagg, J. Org. Chem., 2008, 73, 369-373.

39 M. F. Oldfield, L. Chen and N. P. Botting, J. Labelled Compd. Radiopharm., 2007, 50, 1266-1271.
40 S.-T. Chung, Y.-T. Huang, H.-Y. Hsiung, W.-H. Huang, C.-W. Yao and A.-R. Lee, Chem. Biodiversity, 2015, 12(4), 685-696.

41 J. D. Williams, M. C. Torhan, V. R. Neelagiri, C. Brown, N. O. Bowlin, M. Di, C. T. McCarthy, D. Aiello, N. P. Peet, T. L. Bowlin and D. T. Moir, Bioorg. Med. Chem., 2015, 23(5), 1027-1043.

42 H. Choe, J. Kim and S. Hong, Bioorg. Med. Chem. Lett., 2013, 23, 4324-4327.

43 G. P. Sang, P. Schimmel and S. Kim, Proc. Natl. Acad. Sci. U. S. A., 2008, 105, 11043-11049.

44 X.-D. Wang, R.-C. Deng, Y. Liu, B. Li, S. Huang, H. Ouyang and Z.-P. Xiao, Asian J. Chem., 2014, 26, 8015-8018.

45 H. Mohammad, A. S. Mayhoub, A. Ghafoor, M. Soofi, R. A. Alajlouni, M. Cushman and M. N. Seleem, J. Med. Chem., 2014, 57, 1609-1615.

46 M. Hassani, W. Cai, K. H. Koelsch, D. C. Holley, A. S. Rose, F. Olang, J. P. Lineswala, W. G. Holloway, J. M. Gerdes, M. Behforouz and H. D. Beall, J. Med. Chem., 2008, 51, 3104-3115. 